\title{
Application of Plant Essential Oils in Controlling Wood Mold and Stain Fungi
}

\author{
La Hu, Lizhe Qin, Junkang Xie, Huilan Xu, and Zhangqi Yang* \\ The antifungal activities of 19 plant essential oils against six wood mold \\ and stain fungi (Aspergillus niger, Penicillium citrinum, Trichoderma viride, \\ Botryodiplodia theobromae, Fusarium moniliforme, and Alternaria \\ alternata) were investigated with the in vitro medium method. The \\ chemical compositions and volatilization rates of the essential oils were \\ analyzed by gas chromatography-mass spectrometry and oven heating, \\ respectively. Antifungal effects of the essential oils on fresh Pinus \\ massoniana wood were evaluated by dipping treatment. The average \\ antifungal efficacies of the essential oils varied from 0.1 to 1.0 , and oils of \\ Cinnamomum cassia, Syzygium aromaticum, and Thymus mongolicus \\ showed the greatest antifungal activities and completely inhibited the \\ growth of all six fungi. The essential oils presented great differences in \\ their main chemical components, and a significant negative linear \\ correlation (Pearson correlation coefficient $=-0.627, p<0.01$ ) was found \\ between antifungal efficacy and volatilization rate, indicating that both \\ chemical composition and volatilization rate are important factors \\ influencing the antifungal activities of essential oils. Eight essential oils \\ effectively inhibited the growth of fungi in Pinus massoniana wood with an \\ absorption of $65.51 \mathrm{~g} / \mathrm{m}^{2} \pm 13.78 \mathrm{~g} / \mathrm{m}^{2}$, and they have the potential to be \\ environmentally friendly anti-mildew agents.
}

Keywords: Plant essential oils; Antifungal activity; Mold and stain fungi; Chemical composition; Volatilization rate

Contact information: Guangxi Forestry Research Institute, Guangxi Key Laboratory of Superior Timber Trees Resource Cultivation, Engineering Research Center of Masson Pine of State Forestry

Administration, Nanning 530002, Guangxi, China; *Corresponding author: yangzhangqi@163.com

\section{INTRODUCTION}

Fresh timbers from some important plantations (such as those of Pinus massoniana and Hevea brasiliensis) in southern China are prone to suffering from infection by mold and stain fungi. Although fungal colonization and disfigurement of wood usually have no substantial effect on its density and mechanical properties, they are detrimental to its aesthetic value and cause economic losses (Salem et al. 2016; Chang et al. 2018). Therefore, effective prevention of fungal growth is beneficial to resource saving and the value-added utilization of plantation wood.

Environmentally friendly natural products have attracted increasing attention in protecting wood and wood-based materials against deteriorating organisms such as fungi, bacteria, and termites (Singh and Singh 2012). Some extracts from plants (Mohareb et al. 2013), heartwood (Belt et al. 2018), and seeds (Chang et al. 2018) inhibit wood decay fungi and mold fungi. Among these extracts, plant essential oils are secondary metabolites of natural plants and have a complex chemical composition, mainly including terpenoid derivatives, aromatic compounds, and aliphatic compounds (Pandey et al. 2017). They 
exhibit antioxidative and antibacterial characteristics, health benefits, and mosquito repellency owing to the variety of functional groups in their molecules, and they are thus widely used in the food, pharmaceutical, agricultural, and textile industries (Jugreet et al. 2020). Considering their wide variety of sources and good antifungal properties, plant essential oils show great potential for controlling wood mold and stain fungi. They can be used to treat wood by impregnating, brushing or spraying, to prevent fresh felled logs from fungi infection, or to prevent air-dried or kiln-dried timbers from fungi infection especially in hot and humid weather during storage. For the wood applied in furniture or buildings, plant essential oils can be used to protect the products from mold and stain fungi, or to provide the products with special fragrance. Nevertheless, the effect of the essential oil treatment on wood bonding and finishing performance and the persistence of fragrance remain to be investigated.

Recently, many studies have been done on applying plant essential oils to wood protection. For in vitro antifungal tests, essential oils from Cinnamomum osmophloeum (Wang et al. 2005), Eucalyptus (Varshney et al. 2012), Egyptian plants (Mohareb et al. 2013), Lippia origanoides (Medeiros et al. 2016), and Origanum vulgare (Xie et al. 2017) were reported to have strong inhibitory effects on typical wood decay fungi, while essential oils of geranium, cinnamaldehyde, and eugenol inhibit the growth of four sapstain fungi at a concentration of 1\% w/v (Chittenden and Singh 2011). In in vivo antifungal tests on wood samples, cinnamon oil completely inhibited the growth of Aspergillus niger on rubber wood (Ma-in et al. 2014), and essential oils from Pinus rigida wood completely inhibited the growth of four common mold fungi (Alternaria alternata, Fusarium subglutinans, Chaetomium globosum, and Aspergillus niger) on wood surfaces of Pinus sylvestris, Pinus rigida, and Fagus sylvatica (Salem et al. 2016). Additionally, oils from myrtlewood, orange, lime, and Leyland cypress needles significantly improved the anti-fungal activity of Bacillus subtilis B26 (Wang et al. 2012). However, as far as the authors know, few studies have focused on the antifungal activities of plant essential oils against wood mold and stain fungi in common occurrence in China's forestry.

In this study, the antifungal efficacies of nineteen plant essential oils against six common deteriorating mold and stain fungi on plantation timbers in China were investigated. The chemical compositions and volatilization rates of the essential oils were further analyzed to illustrate their antifungal activities. The actual antifungal effects of essential oils on Pinus massoniana wood blocks were also evaluated.

\section{EXPERIMENTAL}

\section{Materials}

Logs with a length of $1 \mathrm{~m}$ were obtained from a freshly felled 25-year-old Pinus massoniana and immediately sawn to timbers. The timbers from the sapwood were then processed to $50 \mathrm{~mm}$ (longitudinal) $\times 20 \mathrm{~mm} \times 5 \mathrm{~mm}$ blocks and stored frozen until use.

Nineteen plant essential oils (Table 1) were purchased from Guangzhou Bosilin Co., Ltd. (Guangzhou, China). Three wood mold fungi (Aspergillus niger, Penicillam citrinum, and Trichoderma viride) and three wood stain fungi (Botryodiplodia theobromae, Fusarium moniliforme, and Alternaria alternata) were provided by the China Forestry Culture Collection Center (Beijing, China). Potato dextrose agar (PDA, BR grade) nutrient medium was purchased from Qingdao Hope Bio-Technology Co., Ltd. (Qingdao, China). Sterile water was made in the laboratory. 
Table 1. Basic Information about Plant Essential Oils

\begin{tabular}{|c|c|c|c|c|}
\hline No. & Plant Species & Source & $\begin{array}{c}\text { Extraction } \\
\text { Method }\end{array}$ & Color \\
\hline 1 & Laurus nobilis & Leaves & Distillation & Brownish red \\
\hline 2 & Cedrus deodara & Leaves, wood & Distillation & Light yellow \\
\hline 3 & Cinnamomum cassia & Buds, bark and leaves & Distillation & Light yellow \\
\hline 4 & Cupressus sempervirens & Leaves, cones & Distillation & Colorless \\
\hline 5 & Eucalyptus robusta & Leaves & Distillation & Colorless \\
\hline 6 & Syzygium aromaticum & Leaves, buds & Distillation & Orange-yellow \\
\hline 7 & Pelargonium $\times$ hortorum & Leaves & Distillation & Light green \\
\hline 8 & Lavandula angustifolia & Flowers & Distillation & Colorless \\
\hline 9 & Cymbopogon citratus & Stem, leaves & Distillation & Light yellow \\
\hline 10 & Myristica fragrans & Fruits & Distillation & Light yellow \\
\hline 11 & Citrus sinensis & Fruits & Squeeze & Light yellow \\
\hline 12 & Mentha haplocalyx & Flowers, leaves & Distillation & Colorless \\
\hline 13 & Pinus & Leaves, cones & Distillation & Light green \\
\hline 14 & Rosmarinus officinalis & Flowers, leaves & Distillation & Colorless \\
\hline 15 & Ormosia henryi & Wood & Distillation & Colorless \\
\hline 16 & Thymus mongolicus & Leaves, flowers & Distillation & Orange-yellow \\
\hline 17 & Camellia sinensis & Leaves & Distillation & Colorless \\
\hline 18 & Styracaceae & Resin & Distillation & Brown \\
\hline 19 & Ilex chinensis & Leaves & Distillation & Colorless \\
\hline
\end{tabular}

\section{Methods}

In vitro antifungal test

The test was conducted according to the method used in Chittenden and Singh (2011) and Mohareb et al. (2013). A solution of the nutrient medium was prepared by steaming $46 \mathrm{~g}$ of the PDA and $1000 \mathrm{~mL}$ of sterile water at $115^{\circ} \mathrm{C}$ for $30 \mathrm{~min}$ in a pressure steam sterilizer (LDZM-80KCS, Shanghai Medical Instruments Co., Ltd., Shanghai, China). The solution was poured into sterilized 9-mm Petri dishes to obtain solid plate mediums in a clean bench (SW-CJ-IFD, Suzhou Purification Equipment Co., Ltd., Suzhou, China). The strains of the test fungi were transferred with inoculating needles to the centers of the mediums and cultivated in a climate chamber (temperature $27^{\circ} \mathrm{C}$, relative humidity $65 \%$ ) for 1 week until the colonies matured.

A nutrient medium solution was prepared following the above method and stored in a water bath at $65^{\circ} \mathrm{C}$. The medium solution was mixed evenly with plant essential oils $(0.05 \mathrm{vol} \%)$ in a $50-\mathrm{mL}$ centrifuge tube by a vortex mixer and poured into sterilized Petri dishes to obtain an amended solid plate medium. The discs of mature fungi colonies (5$\mathrm{mm}$ diameter) were transferred to the center of the plate medium and placed in the climate chamber (temperature $27^{\circ} \mathrm{C}$, relative humidity 65\%) to cultivate. Three replicates were set for each treatment, and mediums without plant essential oils were used as the control group. The growth of the fungi was observed daily, and the test was ended when the control colony filled the whole medium. The final diameter of the colony was measured by the cross-over method. The antifungal efficacy was calculated as $\left(D_{1}-D_{2}\right) / D_{1}$, where $D_{1}$ and $D_{2}$ are the colony diameters of the control and amended samples, respectively. 


\section{Measurement of chemical compositions and volatilization rates of plant essential oils}

The chemical compositions of the plant essential oils were analyzed by a gas chromatography-triple quadrupole mass spectrometer (SCION SQ-TQ, Bruker, Billerica, MA, USA) equipped with a flame ionization detector (FID) and a DB-5 capillary column $(30 \mathrm{~m} \times 0.32 \mathrm{~mm} \times 0.25 \mu \mathrm{m})$. Helium was used as the carrier gas, and the oven temperature program was as follows: $55{ }^{\circ} \mathrm{C}(3 \mathrm{~min}), 70{ }^{\circ} \mathrm{C}$ to $250{ }^{\circ} \mathrm{C}\left(3{ }^{\circ} \mathrm{C} / \mathrm{min}\right)$, and $250{ }^{\circ} \mathrm{C}(5 \mathrm{~min})$. Samples $(1 \mu \mathrm{L})$ were injected with a split ratio of $50: 1$, and the temperatures of the vaporization chamber and detector were $250{ }^{\circ} \mathrm{C}$. The electron bombardment source was electron ionization (EI) with an electron energy of $70 \mathrm{eV}$, and the ion source temperature was $250^{\circ} \mathrm{C}$. The interface temperature was $250^{\circ} \mathrm{C}$, and the solvent delay time was $3 \mathrm{~min}$.

The essential oil sample $(2 \mathrm{~mL})$ was transferred into a $5-\mathrm{mL}$ centrifuge tube by a pipette and heated in an oven $\left(60{ }^{\circ} \mathrm{C}\right)$ for $3 \mathrm{~h}$. The initial and final weights of the essential oil were recorded. The volatilization rate was calculated as $\left(m_{1}-m_{2}\right) /(S \cdot t)$, where $m_{1}$ and $m_{2}$ are the initial and final masses of the essential oil, and $S$ and $t$ are the liquid surface area and volatilization time, respectively. Ultrapure water was taken as the control group, and three replicates were used for each essential oil.

Antifungal effect of plant essential oils on Pinus massoniana wood

This test was conducted referring to the Chinese standard GB/T 18261 (2013) with some modifications. Frozen wood blocks were taken out, thawed for $30 \mathrm{~min}$, and dipped into beakers with plant essential oils for $10 \mathrm{~min}$. The weights of the blocks before and after treatment were recorded to determine the absorption of the oils. The PDA solid plate mediums were prepared following the above method, and two sterilized glass rods were parallelly placed on the medium. Two treated blocks were then put on the glass rods, and the Petri dishes were transferred into the climate chamber (temperature $28{ }^{\circ} \mathrm{C}$, relative humidity $85 \%$ ) for 4 weeks. Six replicated blocks were used for each essential oil treatment, and untreated blocks were set as the control group. The number of blocks with growing fungi was recorded weekly. The inhibitory efficacy of a plant essential oil was simply measured by the number of blocks without fungi divided by the total number of blocks used. Pearson correlation analysis and least squares regression analysis were used to investigate the relationship between antifungal efficacy and volatilization rate with SPSS Statistics.

\section{RESULTS AND DISCUSSION}

\section{Antifungal Efficacies of Plant Essential Oils}

The antifungal efficacies of the selected plant essential oils against the six fungi are presented in Fig. 1. The average antifungal efficacy varied from 0.1 to 1.0, indicating substantial differences in antifungal activity among these essential oils. The essential oils of C. cassia (\#3), S. aromaticum (\#6), and T. mongolicus (\#16) showed the greatest antifungal activities and completely inhibited the growth of all wood mold and stain fungi. The essential oil of $C$. citratus (\#9) also had high antifungal activity, effectively inhibiting the growth of five fungi (all except Penicillam citrinum). The essential oils of $L$. nobilis (\#1), P. × hortorum (\#7), Styracaceae (\#18), and I. chinensis (\#19) showed moderate antifungal activities, with average antifungal efficacies of 0.5 to 0.7 . The remaining ten categories of essential oils presented relatively poor antifungal activities, having average antifungal efficacies of 0.1 to 0.4 . Additionally, the average antifungal efficacies of the 
nineteen essential oils against $A$. niger, $P$. citrinum, $T$. viride, $B$. theobromae, $F$. moniliforme, and A. alternata were $0.3,0.3,0.5,0.5,0.6$, and 0.6 , respectively. The variation in antifungal efficacy of plant essential oils with different sources has also been demonstrated in other reports (Ma-in et al. 2014; Xie et al. 2017).

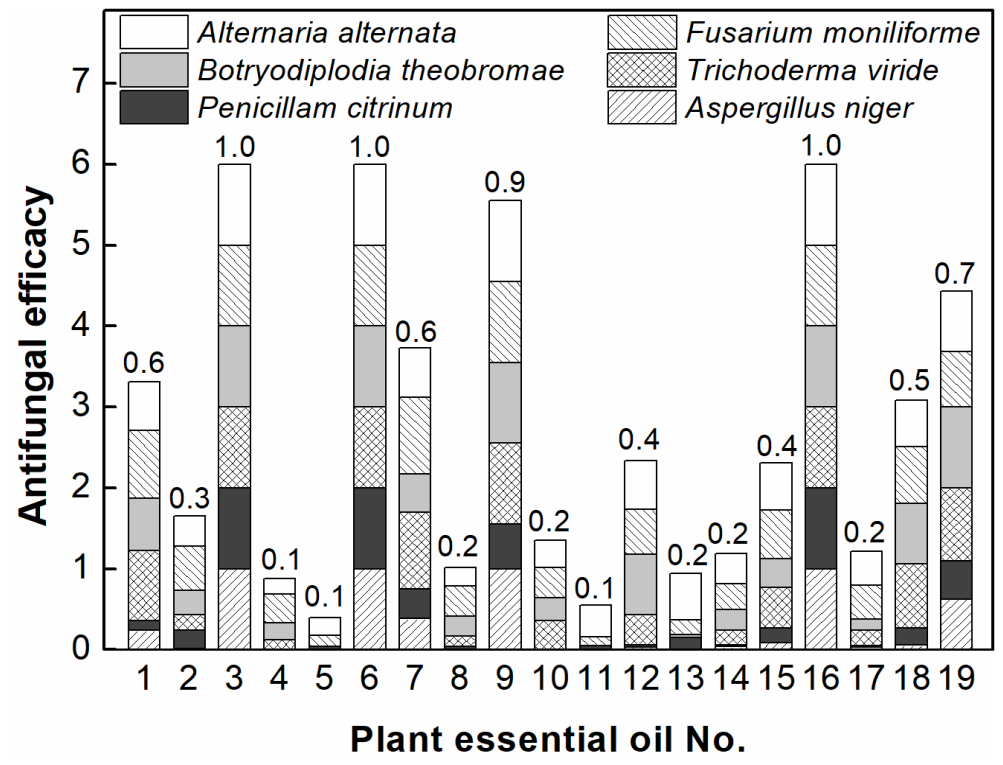

Fig. 1. Antifungal efficacies of plant essential oils against wood mold and stain fungi. Numbers above the columns represent the average antifungal efficacies of the plant essential oils against the six fungi. The height of each different section in a bar represents the antifungal efficacy of the essential oil against the corresponding fungal.

\section{Chemical Compositions of Plant Essential Oils}

The main chemical compositions (constituents with concentrations greater than 5\%) of the nineteen plant essential oils are shown in Table 2. Thirty-seven chemicals were determined, and 1 to 5 constituents were found for each essential oil. Although a few compounds such as d-limonene, $\alpha$-pinene, eugenol, and linalool were present in several essential oils, the chemical components of the samples presented notable differences overall. These differences should be an important reason for their variation in antifungal activity. The most abundant components in the essential oils of $C$. cassia (\#3), $S$. aromaticum (\#6), and C. citratus (\#9) were consistent with previous reports (Deng et al. 2014; Ma-in et al. 2014; Xie et al. 2017), whereas obvious differences were found in some other constituents due to the variations in raw materials and the extraction process.

The strong fungicidal activities of cinnamaldehyde, eugenol, and thymol (Xie et al. 2017) accounted for the high antifungal efficacies of the essential oils of $C$. cassia (\#3), $S$. aromaticum (\#6), and T. mongolicus (\#16). In contrast, the main constituents such as $\alpha$ pinene, 1,8-cineole, and d-limonene from essential oils with low antifungal efficacies should have poor antifungal activities. Moreover, the antifungal activities of the essential oils were also influenced by the concentrations of the constituents (Salem et al. 2016; Xie et al. 2017). For example, plant essential oils of S. aromaticum (\#6), Laurus nobilis (\#1), and Myristica fragrans (\#10), with eugenol concentrations of $87.19 \%, 24.78 \%$, and $6.50 \%$, had average antifungal efficacies of $1.0,0.6$, and 0.2 , respectively. It is suggested that the types and concentrations of chemical components of plant essential oils are decisive factors for their antifungal activities. 
Table 2. Main Chemical Constituents of Plant Essential Oils

\begin{tabular}{|c|c|}
\hline No. & Constituents and Their Concentrations (\%) \\
\hline 1 & $\beta$-caryophyllene (51.77); eugenol (24.78) \\
\hline 2 & 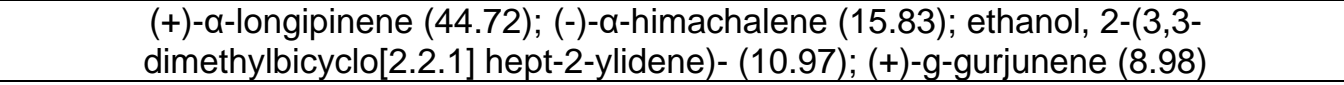 \\
\hline 3 & Cinnamaldehyde (84.46); methyl benzoate (5.03) \\
\hline 4 & a-pinene (64.61); 3-thujene (6.71); bornyl acetate (6.48) \\
\hline 5 & 1,8-cineole (80.44); d-limonene (6.62) \\
\hline 6 & Eugenol (87.19); $\beta$-caryophyllene (10.24) \\
\hline 7 & Citronellol (29.66); neryl alcohol (25.01); 3,7-dimethyl-1-octene (13.76); linalool (11.29) \\
\hline 8 & Linalyl anthranilate (69.64); linalool (19.16) \\
\hline 9 & Geranial (49.30); neral (34.70); neryl alcohol (7.86) \\
\hline 10 & $\begin{array}{c}\text { d-limonene (34.01); } \alpha \text {-terpineol (19.25); } \alpha \text {-pinene (18.97); eugenol (6.50); gamma- } \\
\text { terpineol (5.82) }\end{array}$ \\
\hline 11 & d-limonene (98.26) \\
\hline 12 & $\begin{array}{c}\text { (+/-)-p-menthan-3-ol (44.65); isomenthone (17.40); d-limonene (9.49); (-)-menthone } \\
(6.22)\end{array}$ \\
\hline 13 & Bornyl acetate (30.45); d-limonene (20.64); camphene (19.62); a-pinene (15.28) \\
\hline 14 & a-pinene (29.00); 1,8-cineole (27.00); L-camphor (25.37); isoborneol (7.25) \\
\hline 15 & Linalool (83.68) \\
\hline 16 & g-terpinene (53.98); thymol (22.92); 1-isopropyl-3-methylbenzene (21.74) \\
\hline 17 & 4-carvomenthenol (56.41); g-terpinene (18.88); a-terpinene (7.41) \\
\hline 18 & Benzyl benzoate (73.11); cinnamyl alcohol (12.32) \\
\hline 19 & Methyl hydroxybenzoate (99.80) \\
\hline
\end{tabular}

\section{Volatilization Rate and Its Correlation with Antifungal Efficacy}

The volatilization rates of the plant essential oils ranged from $0.13 \mathrm{~g} /\left(\mathrm{m}^{2} \cdot \mathrm{min}\right)$ to $9.18 \mathrm{~g} /\left(\mathrm{m}^{2} \cdot \mathrm{min}\right)$ (Fig. 2), lower than that of the ultrapure water $\left(14.98 \mathrm{~g} /\left(\mathrm{m}^{2} \cdot \mathrm{min}\right)\right)$.

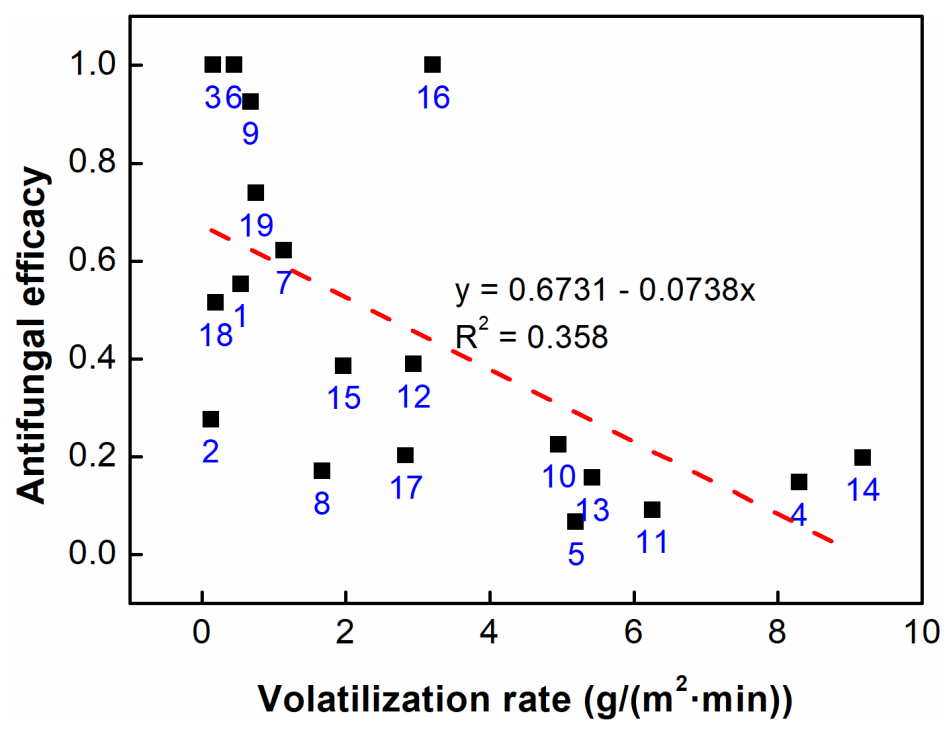

Fig. 2. Correlation between antifungal efficacy and volatilization rate in plant essential oils. Blue numbers below squares represent the identifying numbers of the plant essential oils. 
Interestingly, a significant negative linear correlation (Pearson correlation coefficient $=$ minus $0.627, \mathrm{p}<0.01$ ) was found between antifungal efficacy and volatilization rate. Plant essential oils with high antifungal efficacies $(>0.4)$ showed low volatilization rates $\left(<4 \mathrm{~g} /\left(\mathrm{m}^{2} \cdot \mathrm{min}\right)\right)$, while plant essential oils with high volatilization rates $\left(>4 \mathrm{~g} /\left(\mathrm{m}^{2} \cdot \mathrm{min}\right)\right)$ had low antifungal efficacies $(<0.3)$. However, a few plant essential oils (such as \#2 and \#8) with low volatilization rates $\left(<2 \mathrm{~g} /\left(\mathrm{m}^{2} \cdot \mathrm{min}\right)\right.$ ) also possessed low antifungal efficacies $(<0.3)$. Overall, it seems that plant essential oils with high volatilization rates would rarely have high antifungal activities, though research on more types of plant essential oils is needed.

\section{Inhibitory Effects of Plant Essential Oils on the Growth of Fungi in Wood}

The absorption of the plant essential oils in the block samples was $65.51 \mathrm{~g} / \mathrm{m}^{2} \pm$ $13.78 \mathrm{~g} / \mathrm{m}^{2}$, and their inhibitory efficacies on fungi growth in the wood is presented in Fig. 3. After 4 weeks of testing, plant essential oils \#1, \#3, \#6, \#7, \#9, \#16, \#17, and \#18 completely inhibited the growth of fungi in Pinus massoniana wood, while the inhibitory efficacies of \#2, \#4, \#5,\#13, and \#14 essential oils were 0 . The in vitro antifungal efficacies of the plant essential oils were generally consistent with their inhibitory efficacies (Mohareb et al. 2013). However, the overall inhibitory effects of the essential oils were superior to the in vitro antifungal activities, probably due to their greater loadings (approximately $3.39 \mathrm{vol} \%$ ) in the blocks test. Notably, the inhibitory efficacies of ten of the essential oils substantially decreased as the test time extended from 1 week to 4 weeks, indicating that the antifungal activities of some plant essential oils had validity periods.

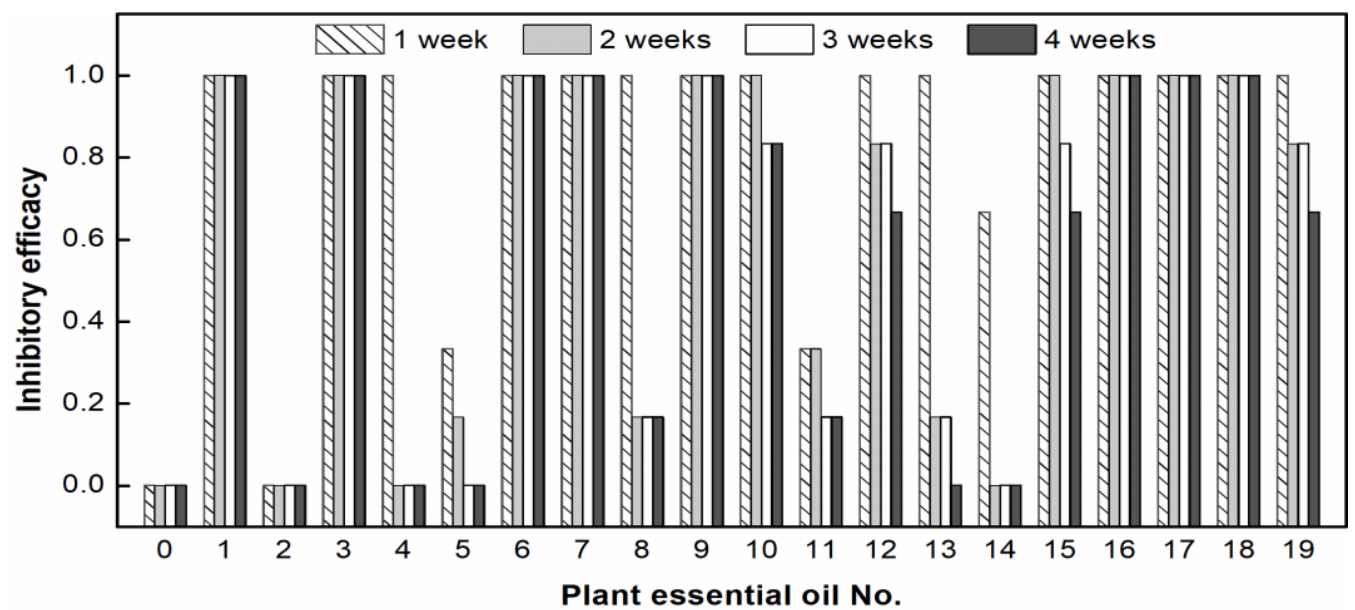

Fig. 3. Inhibitory efficacies of plant essential oils on fungi growth in Pinus massoniana wood. No. 0 - control experimental group

The appearances of the Pinus massoniana wood blocks after the test are shown in Fig. 4. For the control group, mycelium growth was observed in all six samples after only 3 days, which confirmed that fresh Pinus massoniana wood is easily infected by mold and stain fungi. The mycelia on different block samples showed diversity in their colors and morphologies, possibly owing to the effects of the plant essential oils on fungi growth and the variation of fungi within the fresh wood. Some of the tested plant essential oils (such as \#1, \#3, \#6, and \#7) effectively prevented fungal colonization and disfigurement of the wood samples, and they have the potential to be developed as environmentally friendly wood protectants against mold and stain fungi. 

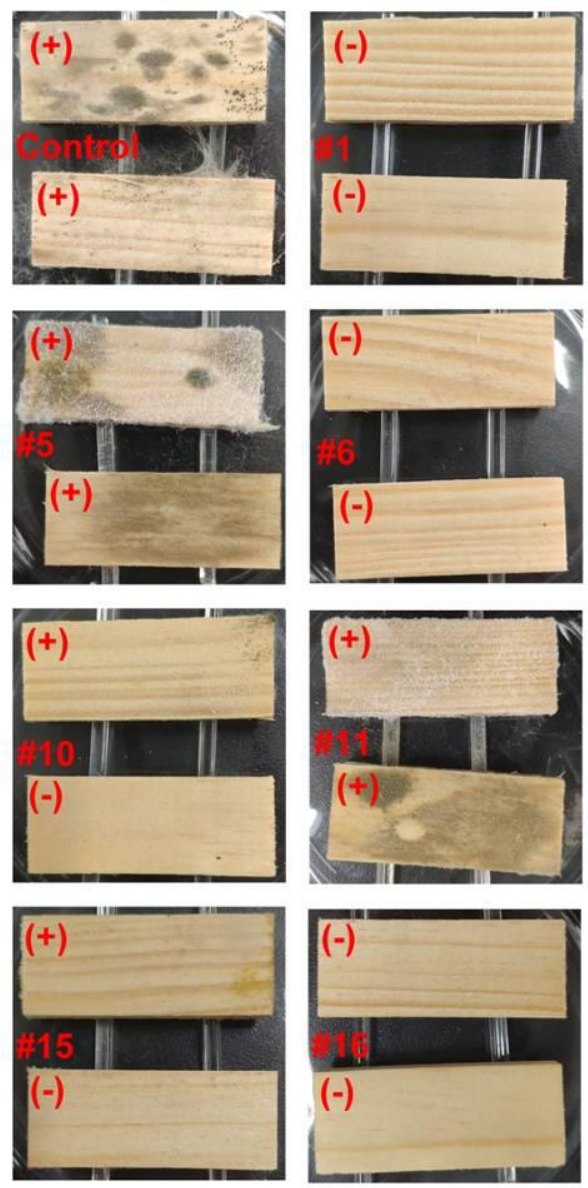
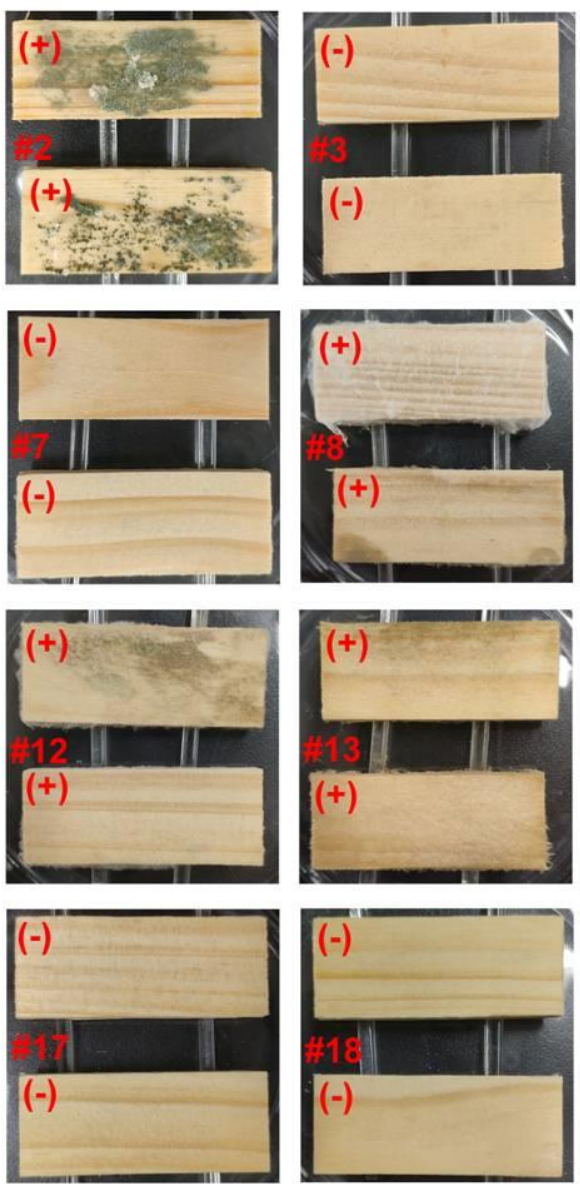
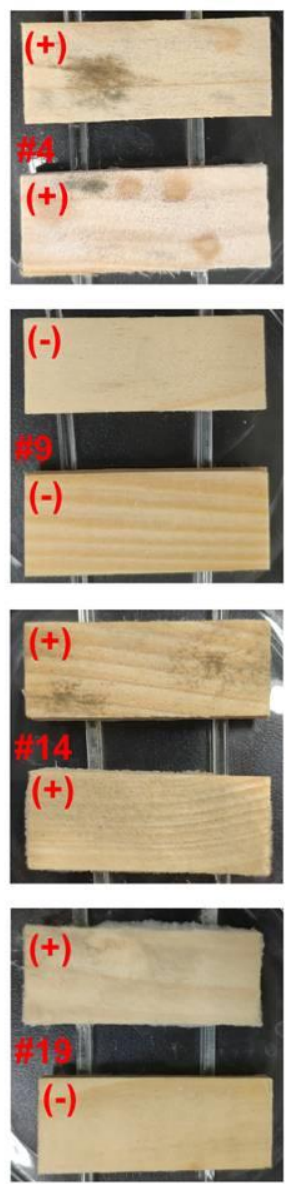

Fig. 4. Appearances of the Pinus massoniana wood blocks after the antifungal effects test. Plus $(+)$ and minus (-) signs represent growth and non-growth of fungi on the blocks, respectively.

\section{CONCLUSIONS}

1. The average in vitro antifungal efficacies of the plant essential oils varied from 0.1 to 1.0, and C. cassia, S. aromaticum, and T. mongolicus showed the greatest antifungal activities and completely inhibited the growth of all six fungi.

2. Thirty-seven main constituents were determined in the plant essential oils. The essential oils presented great differences in their main chemical components, indicating that chemical composition was an important factor influencing the antifungal activities of the essential oils.

3. The volatilization rates of the plant essential oils ranged from $0.13 \mathrm{~g} /\left(\mathrm{m}^{2} \cdot \mathrm{min}\right)$ to 9.18 $\mathrm{g} /\left(\mathrm{m}^{2} \cdot \mathrm{min}\right)$, and a significant negative linear correlation (Pearson correlation coefficient $=-0.627, \mathrm{p}<0.01$ ) was found between antifungal efficacy and volatilization rate.

4. The plant essential oils of L. nobilis, C. cassia, $P . \times$ hortorum, S. aromaticum, $C$. citratus, $T$. mongolicus, Styracaceae, and $C$. sinensis completely inhibited the growth of fungi in the Pinus massoniana wood with an absorption of $65.51 \mathrm{~g} / \mathrm{m}^{2} \pm 13.78 \mathrm{~g} / \mathrm{m}^{2}$, 
and they have the potential to be developed as environmentally friendly anti-mildew agents.

\section{ACKNOWLEDGMENTS}

The authors are grateful for the support of the Science and Technology Major Project of Guangxi (Grant No. GUIKE AA17204087-16), the Guangxi Natural Science Foundation (Grant No. 2017GXNSFBA198064), and the Guangxi Science and Technology Base and Talent Special Project (Grant No. GUIKE AD19254004).

\section{REFERENCES CITED}

Belt, T., Mollerup, F., Hänninen, T., and Rautkari, L. (2018). "Inhibitory effects of Scots pine heartwood extractives on enzymatic holocellulose hydrolysis by wood decaying fungi," Int. Biodeter. Biodegr. 132, 150-156. DOI: 10.1016/j.ibiod.2018.03.004

Chang, L., Xu, G., and Wang, L. (2018). "Preparation and antifungal activities of microcapsules of neem extract used in Populus tomentosa deteriorated by three mold fungi," BioResources 13(4), 8373-8384. DOI: 10.15376/biores.13.4.8373-8384

Chittenden, C., and Singh, T. (2011). "Antifungal activity of essential oils against wood degrading fungi and their applications as wood preservatives," Int. Wood Prod. J. 2(1), 44-48. DOI: 10.1179/2042645311y.0000000004

Deng, X., Liao, Q., Xu, X., Yao, M., Zhou, Y., Lin, M., Zhang P., and Xie, Z. (2014). "Analysis of essential oils from cassia bark and cassia twig samples by GC-MS combined with multivariate data analysis," Food Anal. Method. 7(9), 1840-1847. DOI: $10.1007 / \mathrm{s} 12161-014-9821-\mathrm{y}$

GB/T 18261 (2013). "Test method for anti-mildew agents in controlling wood mould and stain fungi," Standardization Administration of China, Beijing, China.

Jugreet, B. S., Suroowan, S., Rengasamy, R. R. K., and Mahomoodally, M. F. (2020). "Chemistry, bioactivities, mode of action and industrial applications of essential oils," Trends Food Sci. Tech. 101, 89-105. DOI: 10.1016/j.tifs.2020.04.025

Ma-in, K., H-Kittikun, A., and Phongpaichit, S. (2014). "Application of plant essential oils in prevention of fungal growth on Para rubber wood," Eur. J. Wood Wood Prod. 72, 413-416. DOI: 10.1007/s00107-014-0790-z

Medeiros, F. C. M. d., Gouveia, F. N., Bizzo, H. R., Vieira, R. F., and Menezzi, C. H. S. D. (2016). "Fungicidal activity of essential oils from Brazilian Cerrado species against wood decay fungi," Int. Biodeter. Biodegr. 114, 87-93. DOI: 10.1016/j.ibiod.2016.06.003

Mohareb, A. S. O., Badawy, M. E. I., and Abdelgaleil, S. A. M. (2013). “Antifungal activity of essential oils isolated from Egyptian plants against wood decay fungi," $J$. Wood Sci. 59, 499-505. DOI: 10.1007/s10086-013-1361-3

Pandey, A. K., Kumar, P., Singh, P., Tripathi, N. N., and Bajpai, V. K. (2017). "Essential oils: Sources of antimicrobials and food preservatives," Front. Microbiol. 7. DOI: 10.3389/fmicb.2016.02161

Salem, M. Z. M., Zidan, Y. E., Mansour, M. M. A., El Hadidi, N. M. N., and Abo Elgat, W. A. A. (2016). "Antifungal activities of two essential oils used in the treatment of three commercial woods deteriorated by five common mold fungi," Int. Biodeter. 
Biodegr. 106, 88-96. DOI: 10.1016/j.ibiod.2015.10.010

Singh, T., and Singh, A. P. (2012). "A review on natural products as wood protectant," Wood Sci. Technol. 46, 851-870. DOI: 10.1007/s00226-011-0448-5

Varshney, V. K., Pandey, A., Onial, P. K., and Dayal, R. (2012). "Antifungal activity of phytochemicals from Eucalyptus hybrid leaves against some plant pathogenic and wood decay fungi," Arch. Phytopathol. Pfl. 45(19), 2347-2354. DOI: 10.1080/03235408.2012.727073

Wang, S.-Y., Chen, P.-F., and Chang, S.-T. (2005). "Antifungal activities of essential oils and their constituents from indigenous cinnamon (Cinnamomum osmophloeum) leaves against wood decay fungi," Bioresource Technol. 96(7), 813-818. DOI: 10.1016/j.biortech.2004.07.010

Wang, Y., Chang, J., Morrell, J. J., Freitag, C. M., and Karchesy, J. J. (2012). “An integrated approach using Bacillus subtilis B26 and essential oils to limit fungal discoloration of wood," BioResources 7(3), 3132-3141.

Xie, Y., Wang, Z., Huang, Q., and Zhang, D. (2017). "Antifungal activity of several essential oils and major components against wood-rot fungi," Ind. Crop. Prod. 108, 278-285. DOI: 10.1016/j.indcrop.2017.06.041

Article submitted: September 9, 2020; Peer review completed: December 5, 2020;

Revised version received and accepted: December 22, 2020; Published: December 23, 2020.

DOI: 10.15376/biores.16.1.1325-1334 